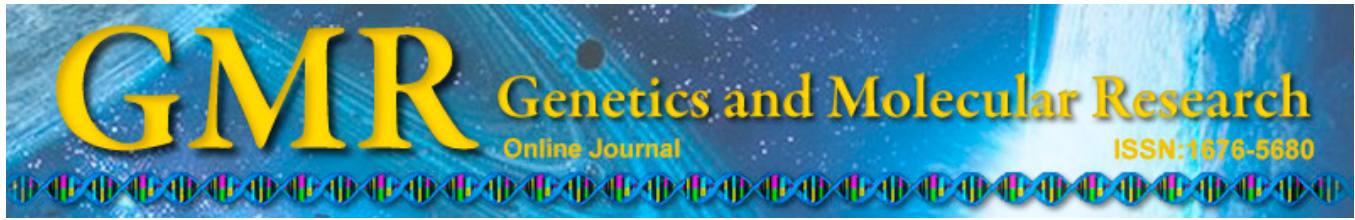

\title{
Interleukin-6 gene $-174 G>C$ polymorphism and chronic obstructive pulmonary disease risk: a meta-analysis
}

\author{
X.M. Xie, R. Ke, Y.H. Zhang, G.Z. Wang, Y.T. Zhu, T. Hussian, \\ L. Yang and M.X. Li \\ Department of Respiratory Medicine, \\ The First Affiliated Hospital of Medical College, \\ Xi'an Jiaotong University, Xi'an, China \\ Corresponding author: M.X. Li \\ E-mail: manxiangli@hotmail.com
}

Genet. Mol. Res. 14 (3): 8516-8525 (2015)

Received December 18, 2014

Accepted April 28, 2015

Published July 28, 2015

DOI http://dx.doi.org/10.4238/2015.July.28.21

\begin{abstract}
Association studies of interleukin-6 (IL-6) -174G $>$ C polymorphism and chronic obstructive pulmonary disease (COPD) have yielded inconsistent results, possibly because single studies often lack sufficient statistical power. A comprehensive search was performed in the PubMed, Embase, Elsevier, Web of Science databases, Wanfang, and the Chinese National Knowledge Infrastructure (CNKI) databases for published studies investigating the associations between IL-6 -174G $>$ C polymorphism and COPD. Odds ratios (OR) and $95 \%$ confidence intervals $(95 \% \mathrm{CI})$ were used to assess the possible associations. Seven studies with a total of 2701 subjects were included in this meta-analysis. A significantly increased risk was detected in the $\mathrm{C}$ allele of the IL-6 $-174 \mathrm{G}>\mathrm{C}$ in Caucasians $(\mathrm{C} v s \mathrm{G}$ : $\mathrm{OR}=1.16,95 \% \mathrm{CI}$ $=1.03-1.30 ; \mathrm{CC}+\mathrm{GC}$ vs $\mathrm{GG}: \mathrm{OR}=1.21,95 \% \mathrm{CI}=1.02-1.42 ; \mathrm{CC}$ vs GG: $\mathrm{OR}=1.32,95 \% \mathrm{CI}=1.03-1.70)$. This meta-analysis suggests that the $\mathrm{C}$ allele of the IL-6 $-174 \mathrm{G}>\mathrm{C}$ might act as a COPD risk factor in
\end{abstract}


Caucasians. Further well-designed case-control studies with larger sample sizes are needed to confirm these conclusions.

Key words: Chronic obstructive pulmonary disease; Interleukin-6; Gene polymorphism; Meta-analysis

\section{INTRODUCTION}

Chronic obstructive pulmonary disease (COPD) is one of the leading causes of morbidity and mortality worldwide, and is characterized by a progressive limitation to airflow caused by an abnormal airway inflammatory response to inhaled particles and fumes (Vestbo et al., 2013). Cigarette smoking is the most important risk factor in the etiopathogenesis of COPD; however, only 10-15\% of all cigarette smokers develop COPD (Hogg and Timens, 2009). This implies that some intrinsic factors, most likely genetic background, might contribute to the individual's susceptibility to COPD.

Polymorphic variants have been currently found in many cytokine genes and are associated with the development of a variety of diseases (Brogger et al., 2006; Galiè et al., 2009; Gingo et al., 2008; Pillai et al., 2009; Sadeghnejad et al., 2009). Interleukin-6 (IL-6) is one such cytokine, and is located on chromosome $7 \mathrm{p} 21$ and functions as a pleiotropic pro-inflammatory and immunomodulatory cytokine. It is secreted by a variety of lymphoid and non-lymphoid cells including $\mathrm{T}$ cells, B cells, monocytes, fibroblasts, hepatocytes, airway endothelial cells, alveolar macrophages, adipocytes, and myocytes as well as other tissues and cells (Hayashi et al., 2000; Fredj et al., 2005; He et al., 2009; Sofi et al., 2009). Accumulated evidence has suggested that IL-6 is involved in the development of COPD (Ferrari et al., 2013), with many clinical studies having reported that $I L-6$ polymorphisms affect the susceptibility of patients to COPD (Seifart et al., 2005; Broekhuizen et al., 2005; Córdoba-Lanús et al., 2008; He et al., 2009; Yanbaeva et al., 2006, 2009). One such polymorphism is the IL-6-174G $>C$ (also called rs1800795) polymorphism in the $I L-6$ promoter. However, other studies have not shown such an association between the IL-6 -174G $>$ C polymorphism and COPD risk (Danilko et al., 2007; Hsieh et al., 2008; Zhou et al., 2012). One reason for this discrepancy could be that all of the above studies were performed in an individual medical center with a small sample size. Therefore, it is important to clarify the relationship between the IL-6 -174G $>$ C polymorphism and COPD susceptibility based on all published studies, and the aim of present study was to address this issue using meta-analysis.

\section{MATERIAL AND METHODS}

\section{Search strategy}

A systematic search was developed in PubMed, Embase, Elsevier, Web of Science databases, Wanfang, and the Chinese National Knowledge Infrastructure (CNKI) databases from inception to October 2014. The following terms were jointly used: ("Interleukin-6" or "IL-6") and ("polymorphism" or "mutation" or "variation") and ("Chronic obstructive pulmonary disease" or "COPD"). The titles and abstracts of all articles identified by the search were screened, and potentially relevant articles were retrieved and assessed according to the criteria in the section that follows. No restriction was placed on time period, sample size, population, language, or types of reports. 


\section{Inclusion and exclusion criteria}

Studies included in this meta-analysis had to meet the following criteria: 1) case-control study in design, 2) evaluated the IL-6 -174G $>$ C polymorphism and COPD susceptibility, 3 ) the genotype frequency was available, and 4) the genotype distribution of the control population was consistent with Hardy-Weinberg Equilibrium (HWE). Studies were excluded if one of the following existed: 1) it was not a case-control genetic study, 2) it was a duplicated report, 3) no useful data were reported, and 4) other $I L-6$ polymorphisms other than $-174 \mathrm{G}>\mathrm{C}$ were investigated. Unpublished data were not considered. Disagreements were resolved by discussion before reaching a consensus. If more than one article was published by the same group using the same cases, the study with the higher sample size was selected.

\section{Data extraction}

Two reviewers collected the data independently and reached a consensus on all items. The following information was extracted from each study: 1) year of publication, 2) name of the first author, 3) ethnicity, 4) sample size, 5) numbers and minor allele frequency of genotypes in cases and controls, 6) genotyping methods, and 7) P value for HWE of the genotypes in the control group. The corresponding or senior authors of all studies included were contacted by e-mail and asked to confirm the data extracted, or provide data where the paper's content was insufficient. In the case of potential duplicate publications, clarification was sought from the authors and the largest single published dataset was used for the meta-analysis.

\section{Statistical methods}

In the present meta-analysis, HWE was tested by the chi-square test, and it was considered statistically significant when the $P$ value was less than 0.05 . Heterogeneity was checked by the Q-test, and it was considered statistically significant when the P value was less than 0.10 . Fixed-effect models are adopted when $\mathrm{P}_{\text {heterogenity }}$ is more than 0.10 , otherwise, the random-effect model was used. We simultaneously evaluated the risk of the dominant allele models, the recessive allele models, and the co-dominant allele models of the IL-6 -174G $>$ C polymorphism with the calculation of crude ORs and $95 \%$ CIs. Sensitivity analysis was carried out by deleting each study at one time. Funnel plots, as well as the Begg rank correlation test and the Egger linear regression test, were used to inspect the potential publication bias, and $\mathrm{P}$ $<0.05$ was considered a significant publication bias. All analyses were conducted using Stata 12.0 (StataCorp. LP, College Station, TX, USA).

\section{RESULTS}

\section{Study characters}

Twenty-five studies were relevant to the search terms outlined in the Materials and Methods (Figure 1). After reviewing the titles, abstracts and articles, 18 studies were excluded. Finally, 7 studies matched the inclusion criteria, and were included in the metaanalysis (Broekhuizen et al., 2005; Seifart et al., 2005; Córdoba-Lanús et al., 2008; Danilko et al., 2007; He et al., 2009; Hsieh et al., 2008; Zhou et al., 2012). All of the studies included 
used peripheral blood samples for DNA extraction. Genotyping was performed by an Illumina BeadStation 500G System Illumina Inc. using the GoldenGate assay technology (Illumina Golden Gate Assay, San Diego, CA, USA) in one study (He et al., 2009), while PCR-restriction fragment length polymorphism was used in the remaining studies. The main features of the studies included in this meta-analysis are presented in Table 1.

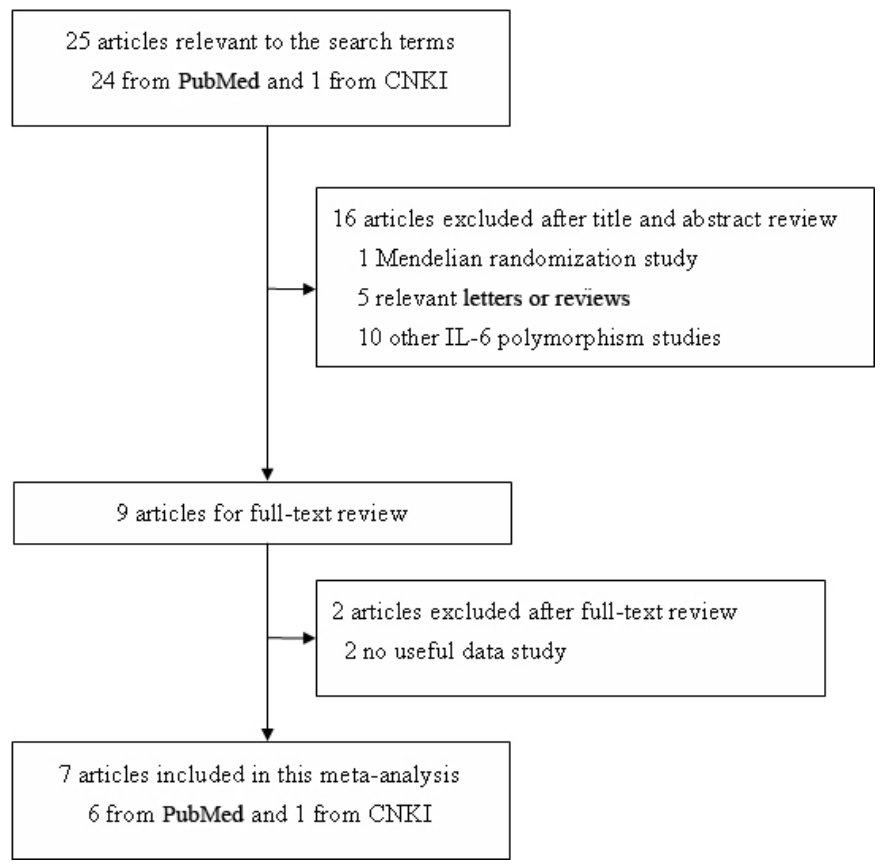

Figure 1. Flow chart of study selection based on the inclusion and exclusion criteria.

\begin{tabular}{|c|c|c|c|c|c|c|c|c|c|c|c|c|}
\hline \multirow[t]{2}{*}{ Study included } & \multirow[t]{2}{*}{ Race } & \multicolumn{4}{|c|}{ Cases } & \multicolumn{4}{|c|}{ Control } & \multirow[t]{2}{*}{ Genotyping method } & \multicolumn{2}{|c|}{ HWE test } \\
\hline & & $\overline{\mathrm{GG}}$ & $\mathrm{GC}$ & $\mathrm{CC}$ & MAF & $\overline{\mathrm{GG}}$ & $\mathrm{GC}$ & $\mathrm{CC}$ & MAF & & $\chi^{2}$ & $\mathrm{P}$ \\
\hline He et al. (2009) & Caucasian & 130 & 189 & 70 & 0.42 & 172 & 194 & 54 & 0.36 & Illumina & 0.004 & 0.95 \\
\hline Córdoba-Lanús et al. (2008) & Caucasian & 82 & 82 & 27 & 0.36 & 159 & 164 & 48 & 0.35 & PCR-RFLP & 0.312 & 0.58 \\
\hline Seifart et al. (2005) & Caucasian & 41 & 52 & 20 & 0.41 & 139 & 158 & 58 & 0.39 & PCR-RFLP & 1.312 & 0.25 \\
\hline Broekhuizen et al. (2005) & Caucasian & 45 & 42 & 11 & 0.33 & 7 & 11 & 2 & 0.38 & PCR-RFLP & 0.601 & 0.44 \\
\hline Danilko et al. (2007) & Caucasian & 110 & 151 & 32 & 0.37 & 153 & 155 & 37 & 0.33 & PCR-RFLP & 0.059 & 0.81 \\
\hline Hsieh et al. (2008) & Asian & 30 & 0 & 0 & 0 & 113 & 2 & 0 & 0.01 & PCR-RFLP & 0.009 & 0.93 \\
\hline Zhou et al. (2012) & Asian & 30 & 0 & 0 & 0 & 30 & 0 & 0 & 0 & PCR-RFLP & NA & NA \\
\hline
\end{tabular}

$\mathrm{MAF}=$ minor allele frequency.

\section{Results of meta-analysis}

The main results of the relationship between IL- $6-174 \mathrm{G}>\mathrm{C}$ polymorphism and COPD risk are listed in Table 2. Overall, a significantly increased risk was detected in the $\mathrm{C}$ allele of the IL-6 -174G $>\mathrm{C}$ polymorphism $(\mathrm{C} v s \mathrm{G}: \mathrm{OR}=1.16,95 \% \mathrm{CI}=1.03-1.30, \mathrm{P}=0.02 ; \mathrm{CC}+\mathrm{GC}$ vs $\mathrm{GG}$, $\mathrm{OR}=1.21,95 \% \mathrm{CI}=1.02-1.42, \mathrm{P}=0.03 ; \mathrm{CC} v s \mathrm{GG}: \mathrm{OR}=1.32,95 \% \mathrm{CI}=1.03-1.70, \mathrm{P}=0.03$ ). 
Studies were then stratified according to ethnicity. Only two small-sample size studies have been published on the association between the IL- $6-174 \mathrm{G}>\mathrm{C}$ polymorphism and COPD among Asians, and the results suggest that the IL-6 -174G $>$ C polymorphism may not be an independent risk factor for COPD susceptibility (Table 1). Furthermore, a markedly increased risk of COPD was found for the IL-6 $-174 \mathrm{G}>\mathrm{C}$ polymorphism among Caucasians $(\mathrm{C}$ vs $\mathrm{G}$ : $\mathrm{OR}=1.16,95 \% \mathrm{CI}=1.03-1.30, \mathrm{P}=0.02 ; \mathrm{CC}+\mathrm{GC}$ vs $\mathrm{GG}: \mathrm{OR}=1.21,95 \% \mathrm{CI}=1.02-1.42, \mathrm{P}=$ 0.03 ; $\mathrm{CC}$ vs GG: $\mathrm{OR}=1.32,95 \% \mathrm{CI}=1.03-1.70, \mathrm{P}=0.03$ ) (Figures $2-4)$.

\begin{tabular}{|c|c|c|c|c|c|c|c|c|}
\hline Subgroup & Statistical models & Genotype/Allele & OR & $95 \% \mathrm{CI}$ & $\mathrm{I}^{2 \%} \%$ & $\mathrm{P}_{\text {heterogeneity }}$ & Analysis model & $\mathrm{P}_{\text {meta }}$ \\
\hline \multirow[t]{3}{*}{ Overall } & Allele model & $\mathrm{C} v s \mathrm{G}$ & 1.16 & $1.03-1.30$ & 0.0 & 0.631 & Fixed & 0.02 \\
\hline & Co-dominant model & $\mathrm{CC} v s \mathrm{GG}$ & 1.32 & $1.03-1.70$ & 0.0 & 0.650 & Fixed & 0.03 \\
\hline & & $\mathrm{GC} v s \mathrm{GG}$ & 1.18 & $0.99-1.40$ & 0.0 & 0.569 & Fixed & 0.07 \\
\hline \multirow[t]{5}{*}{ Caucasian } & Recessive model & $\mathrm{CC} v s \mathrm{GC}+\mathrm{GG}$ & 1.21 & $0.96-1.53$ & 0.0 & 0.777 & Fixed & 0.10 \\
\hline & Dominant model & $\mathrm{CC}+\mathrm{GC} v s \mathrm{GG}$ & 1.21 & $1.02-1.42$ & 0.0 & 0.537 & Fixed & 0.03 \\
\hline & Allele model & $\mathrm{C} v s \mathrm{G}$ & 1.16 & $1.03-1.30$ & 0.0 & 0.497 & Fixed & 0.02 \\
\hline & Co-dominant model & $\mathrm{CC} v s \mathrm{GG}$ & 1.32 & $1.03-1.70$ & 0.0 & 0.650 & Fixed & 0.03 \\
\hline & & $\mathrm{GC} v s \mathrm{GG}$ & 1.18 & $0.99-1.40$ & 0.0 & 0.437 & Fixed & 0.07 \\
\hline \multirow[t]{3}{*}{ Asian } & Recessive model & $\mathrm{CC} v s \mathrm{GC}+\mathrm{GG}$ & 1.21 & $0.96-1.53$ & 0.0 & 0.777 & Fixed & 0.10 \\
\hline & Dominant model & $\mathrm{CC}+\mathrm{GC} v s \mathrm{GG}$ & 1.21 & $1.02-1.43$ & 0.0 & 0.407 & Fixed & 0.03 \\
\hline & - & - & - & _- & - & - & _- & NA \\
\hline
\end{tabular}

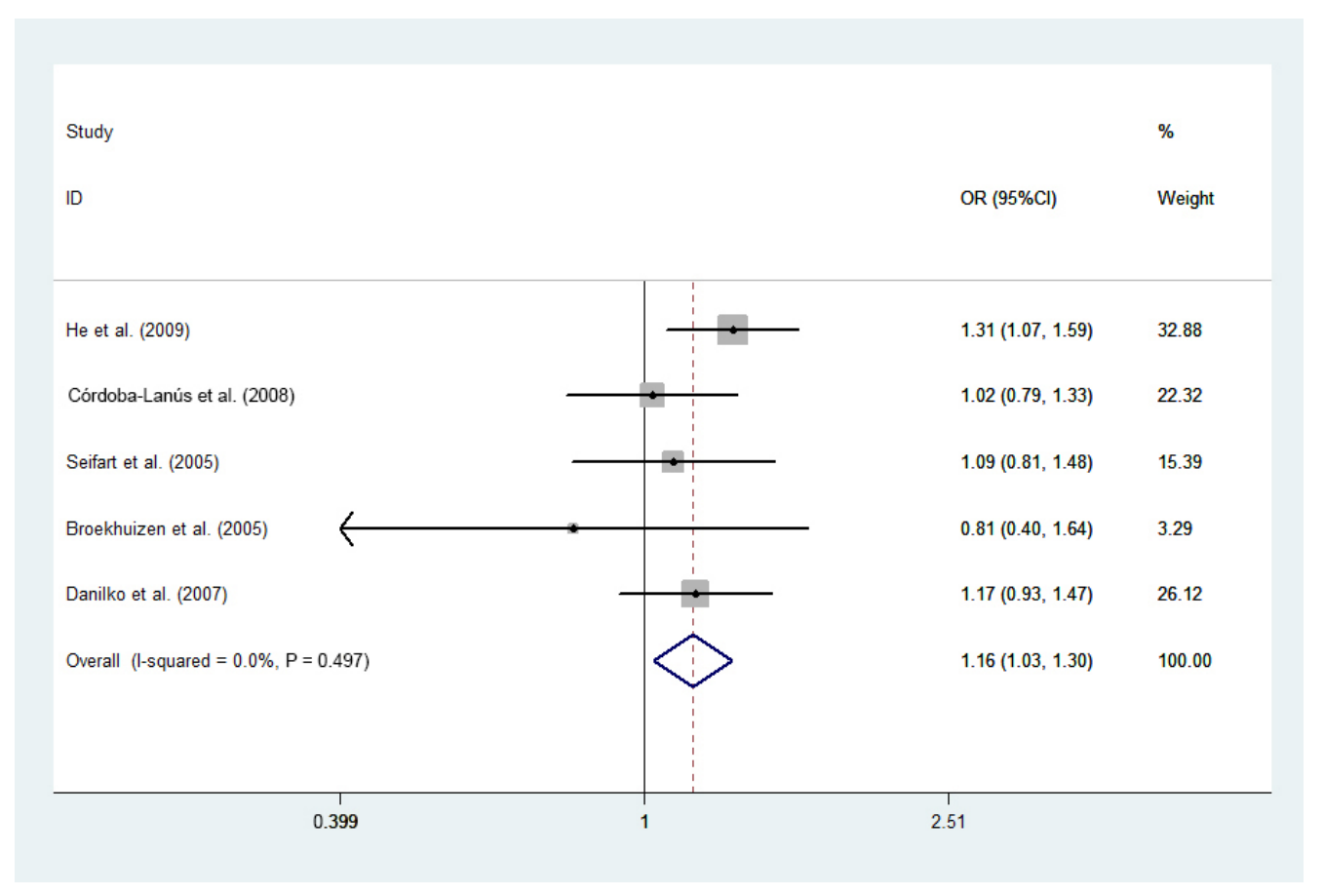

Figure 2. Meta-analysis of the relationship between the IL-6 -174G $>$ C polymorphism and chronic obstructive pulmonary disease risk for $\mathrm{C} v s \mathrm{G}$ in Caucasians. 


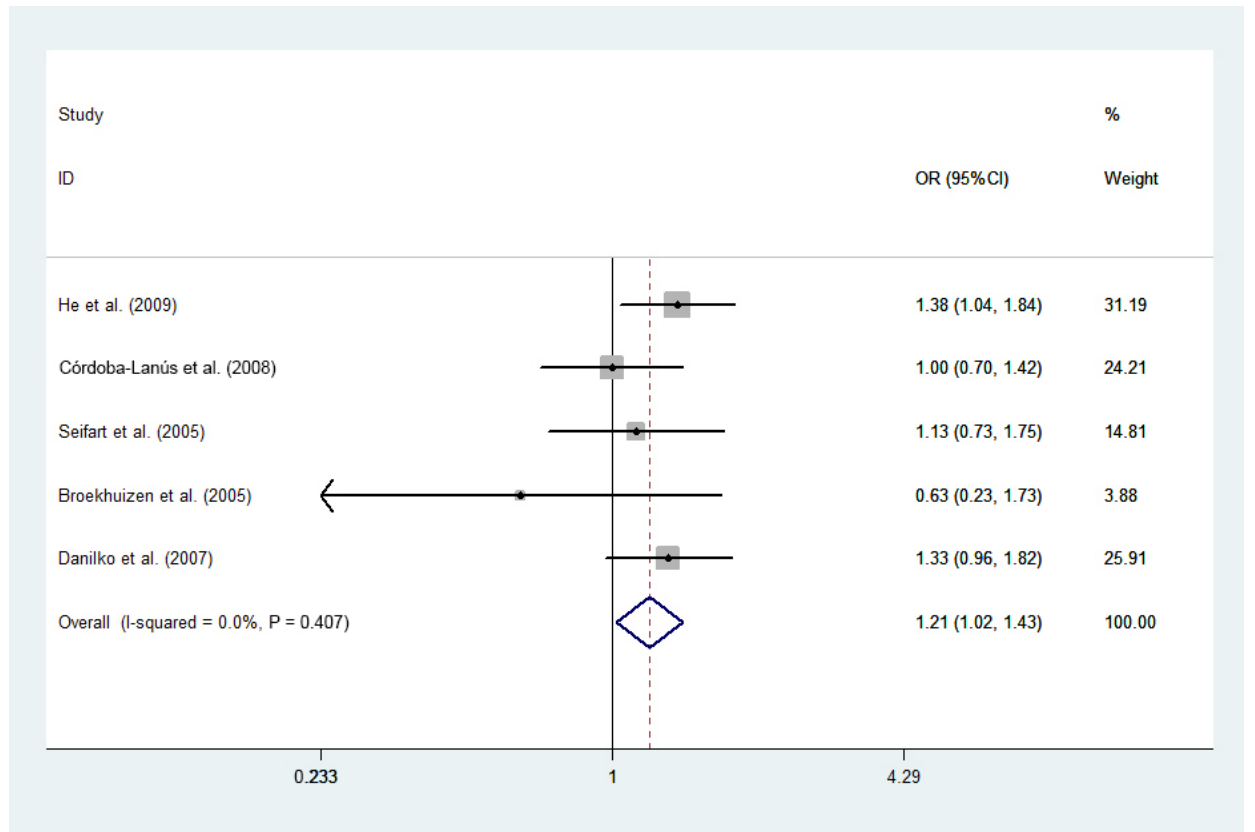

Figure 3. Meta-analysis of the relationship between the IL-6 $-174 \mathrm{G}>\mathrm{C}$ polymorphism and chronic obstructive pulmonary disease risk for $\mathrm{CC}+\mathrm{GC} v s \mathrm{GG}$ in Caucasians.

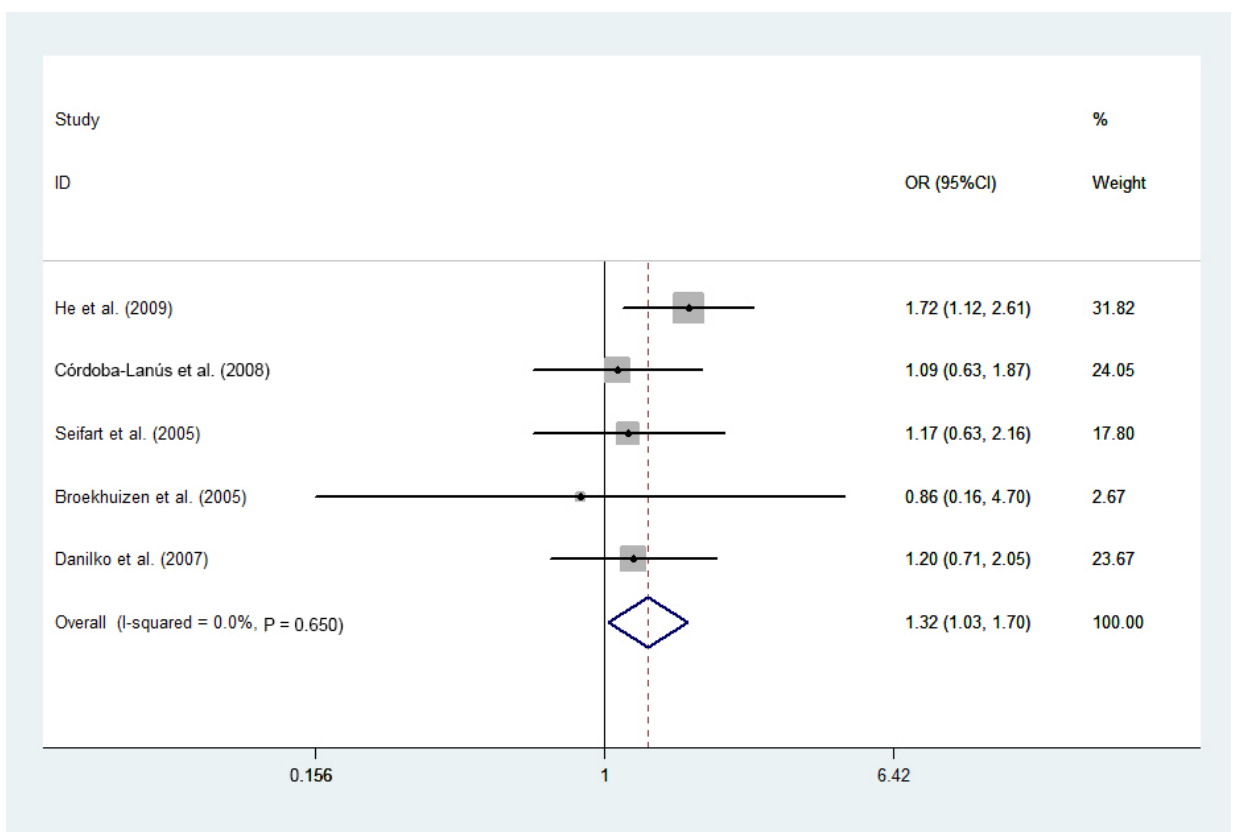

Figure 4. Meta-analysis of the relationship between the IL-6 -174G $>$ C polymorphism and chronic obstructive pulmonary disease risk for $\mathrm{CC} v s \mathrm{GG}$ in Caucasians. 


\section{Test of heterogeneity, sensitivity analyses, and publication bias}

We found that there was no significant heterogeneity between all studies when analyzed for the association between the IL- $6-174 \mathrm{G}>\mathrm{C}$ polymorphism and COPD risk, so we adopted fixed-effect models. The results of the heterogeneity test and statistical models for this meta-analysis are all listed in Table 2. All genotypes in the control groups conformed with the HWE $(\mathrm{P}>0.05)$. We performed a sensitivity analysis for each IL-6 $-174 \mathrm{G}>\mathrm{C}$ polymorphism association by sequentially omitting individual studies. The corresponding pooled ORs were not materially altered, indicating that our results were statistically robust (data not shown). The funnel plot and the Begg test were used to assess publication bias. There was no evidence of publication bias in our study (Figure 5). Results showed that there was no publication bias (all $\mathrm{P}>0.05$ ).

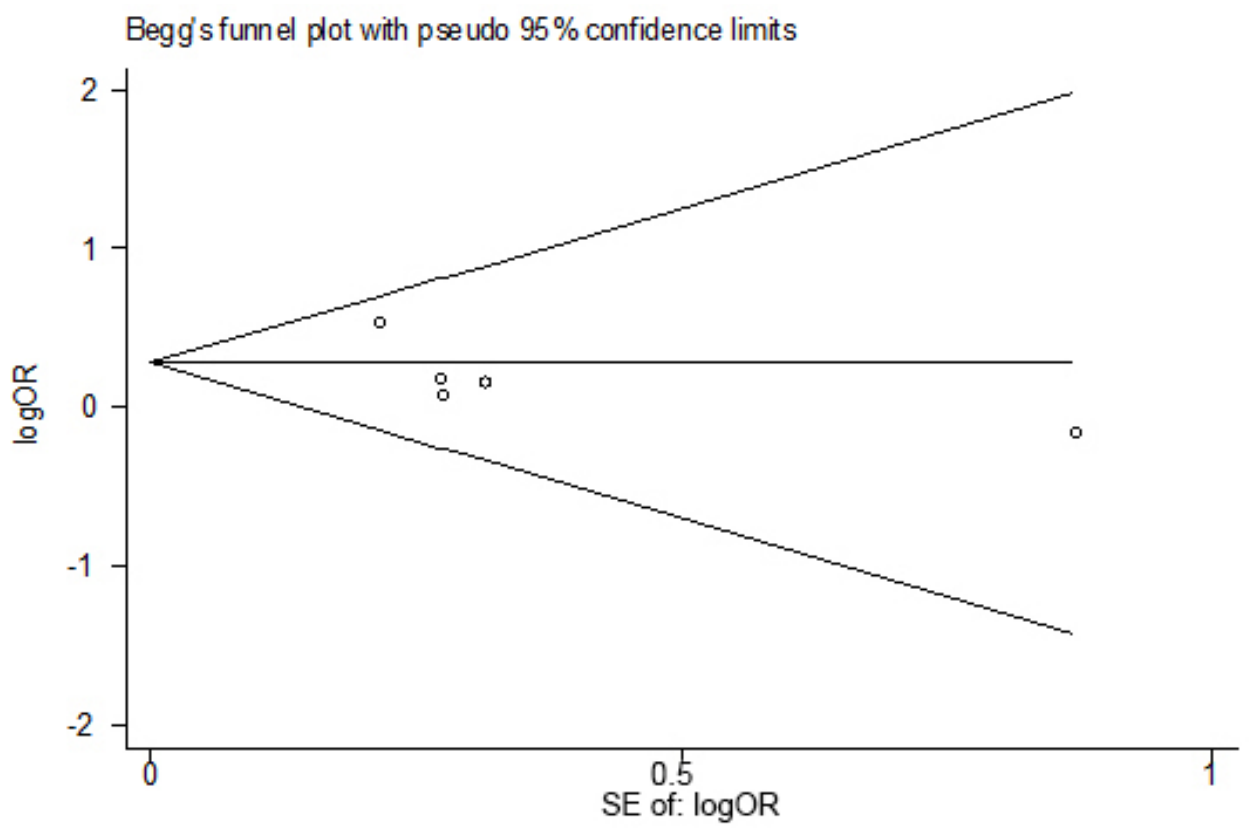

Figure 5. Begg funnel plot test of publication bias for the association of the IL-6 $-174 \mathrm{G}>\mathrm{C}$ polymorphism and chronic obstructive pulmonary disease risk for $\mathrm{CC} v s \mathrm{GG}$ in Caucasians.

\section{DISCUSSION}

Human genetic studies are indispensable in understanding the molecular basis of diseases including COPD. Many candidate genes, including IL-6 (Broekhuizen et al., 2005; Danilko et al., 2007; Córdoba-Lanús et al., 2008; He et al., 2009), IL-8 (Shen et al., 2008), tumor necrosis factor (Küçükaycan et al., 2002), disintegrin and metalloprotease 33 (Sadeghnejad et al., 2009; Wang et al., 2009; Xiao et al., 2011), and beta 2-adrenoceptor (Hegab et al., 2004; Matheson et al., 2006) have been reported to be involved in COPD susceptibility. IL-6 is a 
potential mediator of inflammation in COPD, and has been shown to be increased in serum, exhaled breath condensate, and sputum during stable conditions and exacerbation, predicting a faster decline in forced expiratory volume in one second (Agust1 et al., 2003; Donaldson et al., 2005; He et al., 2009). The most studied IL-6 polymorphism, IL-6 -174G $>$ C, has been shown to be associated with an increased risk of cardiovascular events and related risk factors such as C-reactive protein, fibrinogen, and hypertension (Jenny et al., 2002; Vickers et al., 2002; Chaouat et al., 2009). That being said, the results for the relationship between IL- $6-174 \mathrm{G}>\mathrm{C}$ variants and COPD risk are inconsistent (Broekhuizen et al., 2005; Seifart et al., 2005; Danilko et al., 2007; Córdoba-Lanús et al., 2008; Hsieh et al., 2008; He et al., 2009; Zhou et al., 2012). Therefore, it is critical to systematically evaluate all studies from different groups and to quantify the overall risk associated with the IL- $6-174 \mathrm{G}>\mathrm{C}$ polymorphism and COPD.

We also conducted the stratified analysis by ethnicity to minimize the heterogeneity among different human populations. In the population of Caucasian, a significant association between the IL-6 -174G $>$ C polymorphism and COPD risks was detected in the allele model (C vs G), dominant model (CC+CG vs GG), and co-dominant model (CC vs GG). Since few studies published in Asian population (Hsieh et al., 2008; Zhou et al., 2012), we could not do data synthesis due to limited power. However, we still observed that the $\mathrm{C}$ alleles were not found in these two small-sample size Asian population studies, indicating that the IL-6 $-174 \mathrm{G}>\mathrm{C}$ polymorphism may not be an independent risk factor for COPD susceptibility among the Asian population. These results suggested that the IL- $6-174 \mathrm{G}>\mathrm{C}$ polymorphism might be a risk factor for COPD among Caucasians. However, future studies need to further confirm the results.

Evidence suggests that the allele C of IL-6 $-174 \mathrm{G}>\mathrm{C}$ was higher in COPD patients than those in healthy smoker controls (He et al., 2009). It has been shown that the $-174 \mathrm{G} / \mathrm{C}$ polymorphism of the $I L-6$ promoter region has a direct effect on gene transcription. Allele $\mathrm{C}$ of the IL-6 -174G $>$ C polymorphism is expressed at lower levels in comparison to allele $\mathrm{G}$, which has been previously associated with increased circulating IL-6 levels, cardiovascular disease, and cardiovascular disease-related mortality in populations of older adults (Humphries et al., 2001; Jenny et al., 2002; Mayosi et al., 2005). However, Broekhuizen et al. (2005) did not find an association between the IL-6 -174G $>$ C polymorphism and a cachexia phenotype in subjects with COPD. Moreover, Córdoba-Lanús et al. (2008) reported that the IL-6 -572G $>$ C but not the IL-6 -174G $>$ C polymorphism was associated with COPD. Yanbaeva et al. (2009) were the first to show that a haplotype of the $I L-6$ gene was associated with an increased risk of moderate-to-severe smoking-induced COPD. It is worth mentioning that a recent genomewide association study found the single nucleotide polymorphisms in the IL-6 receptor gene that was associated with lung function phenotypes and COPD (Wilk et al., 2007; Sin and Man, 2008). However, given the frequent lack of reproducibility in genetics (e.g., due to gender, age, smoking history, race etc.), well-designed case-control studies with larger sample sizes are needed to confirm these results.

Several limitations of this study should be addressed. First, only published studies were retrieved in the present study. Furthermore, a publication bias might be possible, even though Funnel plots and the Egger test did not find any publication bias. Second, only two small-sample size studies have been published on the association between the IL- $6-174 \mathrm{G}>\mathrm{C}$ polymorphism and COPD among the Asian population. Therefore, to conduct a more precise analysis of the effect of the polymorphism on COPD risk, additional studies with larger sample sizes and concerning different ethnicities are particularly warranted. Third, the potential 
gene-gene and gene-environment interactions were not addressed due to insufficient data, which might also affect the accuracy of the results. Considering these limitations, the results of the metaanalysis should be interpreted with caution and well-designed case-control studies with larger sample sizes are needed to confirm these results. In summary, this meta-analysis suggested that the $\mathrm{C}$ allele of the IL- $6-174 \mathrm{G}>\mathrm{C}$ polymorphism may act as a COPD risk factor in Caucasians, but not in Asians.

\section{Conflicts of interest}

The authors declare no conflict of interest.

\section{ACKNOWLEDGMENTS}

Research supported by the National Natural Science Foundation of China (Grant \#81070045) and the Key Clinical Project for Affiliated Hospital of Ministry of Public Health of China (Grant \#111).

\section{REFERENCES}

Agustí AG, Noguera A, Sauleda J, Sala E, et al. (2003). Systemic effects of chronic obstructive pulmonary disease. Eur. Respir. J. 21: 347-360.

Broekhuizen R, Grimble RF, Howell WM, Shale DJ, et al. (2005). Pulmonary cachexia, systemic inflammatory profile, and the interleukin 1ß-511 single nucleotide polymorphism. Am. J. Clin. Nutr. 82: 1059-1064.

Brogger J, Steen VM, Eiken HG, Gulsvik A, et al. (2006). Genetic association between COPD and polymorphism in TNF, ADRB2 and EPHX1. Eur. Respir. J. 27: 682.

Chaouat A, Savale L, Chouaid C, Tu L, et al. (2009). Role for interleukin-6 in COPD-related pulmonary hypertension. Chest 136: 678-687.

Córdoba-Lanús E, de-Torres J-P, López-Aguilar C, Rodríguez-Pérez MC, et al. (2008). Association of IL-6 gene polymorphism and COPD in a Spanish Population. Respir. Med. 102: 1805-1811.

Danilko KV, Korytina GF, Akhmidishina LZ, Ianbaeva DG, et al. (2007). Association of cytokines genes (ILL, IL1RN, TNF, LTA, IL6, IL8, IL0) polymorphic markers with chronic obstructive pulmonary disease. Mol. Biol. 41: 26.

Donaldson GC, Seemungal TA, Patel IS, Bhowmik A, et al. (2005). Airway and systemic inflammation and decline in lung function in patients with COPD. Chest 128: 1995-2004.

Ferrari R, Tanni SE, Caram LM, Corrêa C, et al. (2013). Three-year follow-up of interleukin 6 and C-reactive protein in chronic obstructive pulmonary disease. Respir. Res. 14: 24.

Fredj S, Bescond J, Louault C, Delwail A, et al. (2005). Role of interleukin-6 in cardiomyocyte/cardiac fibroblast interactions during myocyte hypertrophy and fibroblast proliferation. J. Cell Physiol. 204: 428-436.

Galiè N, Hoeper MM, Humbert M, Torbicki A, et al. (2009). Guidelines for the diagnosis and treatment of pulmonary hypertension. The Task Force for the Diagnosis and Treatment of Pulmonary Hypertension of the European Society of Cardiology (ESC) and the European Respiratory Society (ERS), endorsed by the International Society of Heart and Lung Transplantation (ISHLT). Eur. Heart. J. 30: 2493-2537.

Gingo MR, Silveira LJ, Miller YE, Friedlander AL, et al. (2008). Tumour necrosis factor gene polymorphism are associated with COPD. Eur. Respir. J. 31: 1005-1012.

Hayashi R, Yamashita N, Matsui S, Fujita T, et al. (2000). Bradykinin stimulates IL-6 and IL-8 production by human lung fibroblasts through ERK- and p38 MAPK-dependent mechanisms. Eur. Respir. J. 16: 452-458.

He J-Q, Foreman MG, Shumansky K, Zhang X, et al. (2009). Associations of IL-6 polymorphism with lung function decline and COPD. Thorax 64: 698-704.

Hegab AE, Sakamoto T, Saitoh W, Massoud HH, et al. (2004). Polymorphism of IL4, IL13, and ADRB2 genes in COPD. Chest 126: 1832-1839.

Hogg JC and Timens W (2009). The pathology of chronic obstructive pulmonary disease. Annu. Rev. Pathol. 4: 435-459.

Hsieh MH, Chong IW, Hwang JJ, Lee CH, et al. (2008). Lack of associations between several polymorphism in cytokine genes and the risk of chronic obstructive pulmonary diseases in Taiwan. Kaohsiung J. Med. Sci. 24: 126-137. 
Humphries SE, Luong LA, Ogg MS, Hawe E, et al. (2001). The interleukin-6 $-174 \mathrm{G}>\mathrm{C}$ promoter polymorphism is associated with risk of coronary heart disease and systolic blood pressure in healthy men. Eur. Heart. J. 22: 2243-2252.

Jenny NS, Tracy RP, Ogg MS, Luong le A, et al. (2002). In the elderly, interleukin-6 plasma levels and the $-174 \mathrm{G}>\mathrm{C}$ polymorphism are associated with the development of cardiovascular disease. Arterioscler. Thromb. Vasc. Biol. 22: 2066-2071.

Küçükaycan M, Van Krugten M, Pennings HJ, Huizinga TW, et al. (2002). Tumor necrosis factor-alpha+ 489G/A gene polymorphism is associated with chronic obstructive pulmonary disease. Respir. Res. 3: 29.

Matheson MC, Ellis JA, Raven J, Johns DP, et al. (2006). $\beta 2$-adrenergic receptor polymorphisms are associated with asthma and COPD in adults. J. Hum. Genet. 51: 943-951.

Mayosi BM, Avery PJ, Baker M, Gaukrodger N, et al. (2005). Genotype at the $-174 \mathrm{G}>\mathrm{C}$ polymorphism of the interleukin- 6 gene is associated with common carotid artery intimal-medial thickness: family study and meta-analysis. Stroke 36: 2215-2219.

Pillai SG, Ge D, Zhu G, Kong X, et al. (2009). A genome-wide association study in chronic obstructive pulmonary disease (COPD): identification of two major susceptibility loci. PLoS Genet. 5: e1000421.

Sadeghnejad A, Ohar J, Zheng S, Sterling DA, et al. (2009). Adam33 polymorphism are associated with COPD and lung function in long-term tobacco smokers. Respir. Res. 10: 21.

Seifart C, Dempfle A, Plagens A, Seifart U, et al. (2005). TNF- $\alpha$-, TNF- $\beta-$, IL-6-, and IL-10-promoter polymorphisms in patients with chronic obstructive pulmonary disease. Tissue Antigens 65: 93-100.

Shen M, Vermeulen R, Chapman RS, Berndt SI, et al. (2008). A report of cytokine polymorphism and COPD risk in Xuan Wei, China. Int. J. Hyg. Environ. Health. 211: 352-356.

Sin DD and Man SP (2008). Interleukin-6 A Red Herring or a Real Catch in COPD? Chest 133: 4-6.

Sofi MH, Li W, Kaplan MH, Chang CH, et al. (2009). Elevated IL-6 expression in CD4 T cells via PKCtheta and NFkappaB induces Th2 cytokine production. Mol. Immunol. 46: 1443-1450.

Vestbo J, Hurd SS, Agusti AG, Jones PW, et al. (2013). Global strategy for the diagnosis, management, and prevention of chronic obstructive pulmonary disease: GOLD executive summary. Am. J. Respir. Crit. Care. Med. 187: 347-365.

Vickers MA, Green FR, Terry C, Mayosi BM, et al. (2002). Genotype at a promoter polymorphism of the interleukin-6 gene is associated with baseline levels of plasma C-reactive protein. Cardiovasc. Res. 53: 1029-1034.

Wang X, Li L, Xiao J, Jin C, et al. (2009). Association of ADAM33 gene polymorphism with COPD in a northeastern Chinese population. BMC Med. Genet. 10: 132.

Wilk JB, Walter RE, Laramie JM, Gottlieb DJ, et al. (2007). Framingham Heart Study genome-wide association: results for pulmonary function measures. BMC Med. Genet. 8: S8.

Xiao J, Han J, Wang X, Hua D, et al. (2011). Association of ADAM33 gene with susceptibility to COPD in Tibetan population of China. Mol. Biol. Rep. 38: 4941-4945.

Yanbaeva DG, Dentener MA, Creutzberg EC, Wouters EF, et al. (2006). Systemic inflammation in COPD: is genetic susceptibility a key factor? COPD 3: 51-61.

Yanbaeva DG, Dentener MA, Spruit MA, Houwing-Duistermaat JJ, et al. (2009). IL-6 and CRP haplotypes are associated with COPD risk and systemic inflammation: a case-control study. BMC Med. Genet. 10: 23.

Zhou A, Yang W, Long F, Chen L, et al. (2012). A study of association between IL-6 promoter polymorphism and COPD risk (Chinese). Chin. J. Gen. Pract. 10: 1257-1258. 